\title{
VIDEO-REFLECTION: AN EMERGING TOOL FOR TRAINING CLIENT CENTRED COMMUNICATION SKILLS IN STAFF SUPPORTING ADULTS WITH LEARNING DISABILITIES IN AN EDUCATION SETTING
}

\author{
Keywords: Video Reflection, Staff training, Adults Learning Disabilities, Intervention, \\ Interaction, Speech and Language Therapy
}

Ben Meadows: ben.meadows890@gmail.com

02085454512

Megan Taylor: megan.a.taylor@hotmail.co.uk

01223713483

Tara Rayment: tara.rayment@nhs.net

01452894280

Jane Johnson: janejohnsonslt@yahoo.co.uk

Merle Mahon: merle.mahon@ucl.ac.uk

02076794036

University College London

2 Wakefield St, Kings Cross, London WC1N 1PJ 


\section{ABSTRACT}

\section{Background and Aims}

Speech and Language Therapists (SLTs) contribute to communication with adults with learning disabilities by providing training to the networks that support them. The requirements for successful communication with this population are frequently complex and necessitate an effective training medium to transfer the target knowledge and skills. Video has increasingly been used as a tool to facilitate self-reflection and behaviour change. Currently there is limited research into the effectiveness of video-based training in education settings for adults with learning disabilities. Therefore, this study investigated the effectiveness of Video-Reflection Training (VRT) for support staff in a college for adults with learning disabilities.

\section{Method and Procedure}

Ten staff members with diverse skill sets completed three VRT sessions aimed at improving their use of communication strategies. Training evaluation measures were taken before and after VRT and included use of communication strategies, self-efficacy, training preconceptions and training experience.

\section{Outcomes and Results}

Overall, the majority of staff made gains either in their use of communication strategies or in their self-efficacy ratings. Yet, study limitations restrict conclusions regarding whether VRT itself caused these outcomes. Interpretation revealed five factors relating to the effectiveness of VRT: tailoring training to staff's pre-existing skills, practising facilitation techniques, providing acceptable training, increasing self-reflection skills and using video as a reflection tool. 


\section{Conclusions and Implications}

Regardless of the limitations, this study provides findings that VRT is a useful tool for training support staff to use client-centred communication skills in an education setting. Future training programmes should be individualised and tailored to staff depending on their skill sets.

\section{Accessible summary}

- Video reflection is one of the best ways to help staff develop their communication skills provided the training setting is supportive.

- Good communication skills are important so staff can support people with learning disabilities access education.

- This study filmed education staff working with people with a learning disability at college.

- The staff watched the video so they could see themselves and think about what they did well and what they could improve on.

- The results found that staff were better at communicating and more confident using their communication skills after watching the video. 


\section{INTRODUCTION}

There is a well-documented, high prevalence of communication difficulties within the learning disabilities population. Up to $90 \%$ of adults with learning disabilities have communication difficulties, with approximately 50\% of these being significant (Kelly, 2002). Communication difficulties vary across individuals and can include impairments of understanding, expression, speech, fluency and social communication (Baker, Oldnall, Birkett, McCluskey \& Morris, 2010).

Communication is a basic human right that is fundamental for citizenship and humanity (Royal College of Speech and Language Therapists [RCSLT], 2013). The UK government's strategies for adults with learning disabilities services, Valuing People and Valuing People Now (Department of Health [DOH], 2001; 2009), emphasise that services should be personcentred and should enable adults with learning disabilities to have the same rights, opportunities and responsibilities as anybody else. Effective communication is essential for accessing and attaining these outcomes (RCSLT, 2013). Thus, reasonable adjustments must be made to meet people's communication needs, in order to counteract vulnerability to a range of risks (RCSLT, 2013).

As many adults with learning disabilities require communication support and generalising newly learned skills can be challenging for them (Money, 1997), direct intervention can have limited effect. Therefore, best practice typically focuses on extrinsic factors that may affect communication success, for instance, the skills of those who support adults with learning disabilities (Baker et al., 2010). A crucial element is training for various communication 
British Journal of Learning Disabilities Manuscript ID BLD-19-0027.R2 Accepted version. 11/12/19

partners with the aim of indirectly optimising adults with learning disabilities' communication skills (Enderby et al., 2009).

Dobson, Upadhyaya \& Stanley (2002) suggest that training should be in the same context that skills will be used, should focus on everyday situations, be person-centred and provided long-term. Arenstein \& Lipson (2013) echoed these recommendations and added goal setting, coaching and use of video-reflection to enable evaluation

A recent UK Government consultation has proposed mandatory learning disability and autism training for health and care staff (Department of Health and Social Care [DHSC], 2019). This outlines a training framework that proposes a three-tiered approach, which identifies the skills and knowledge required by different staff working with people with learning disabilities and/or autism. The consultation suggests three key training content domains, including; 'understanding learning disability and autism', 'legislation and rights' and 'making reasonable adjustments' (e.g. communication, supportive environment, personalisation, good practice e.g. Positive Behaviour Support). The consultation addresses that the delivery of training should include people with learning disabilities and/or autism and needs to be tailored based on the staff's role and the organisational structure. For example training for ancillary staff may involve a more basic awareness of the content domains, which is delivered via E-learning. Whereas support workers who have regular contact would benefit from more detailed training that is delivered during induction and followed up by refreshers throughout employment.

Yet despite recommendations and due to limited resources and service provision constraints, more commonly one off "one size fits all" approaches are utilised involving traditional techniques such as presentations, instruction, role play, modelling and feedback 
(Van Oorsouw, Embregts, Bosman \& Jahoda, 2009). While there is some evidence for the efficacy of traditional techniques (Van Oorsouw et al., 2009), studies can be methodologically weak, for example, not evaluating outcomes for staff (Enderby et al., 2009) and frequently findings show no evidence of maintenance or generalisation of skills (Money, 1997; Van Oorsouw et al., 2009).

Video-reflection training (VRT) has been described as the gold standard of communication training (Kurtz, Silverman \& Draper, 2005) and has been used in a number of diverse fields within healthcare (Kennedy, Landor \& Todd, 2011). VRT commonly involves videoing a staff member communicating with their client and subsequently self-reflecting on their skills in a feedback session. VRT has been described as a powerful tool to develop communication skills (Fukkink, Trieneken \& Kramer, 2011) and is reported to be the singular most successful way to do so (Kennedy et al., 2011). This effectiveness is attributed to VRT providing the unique situation of trainees objectively viewing themselves and self-reflecting on their skills (Fukkink et al., 2011).

There is emerging evidence for VRT's effectiveness for training communication skills of staff that support adults with learning disabilities within residential care settings. Koski, Martikainen, Burakoff and Launonen (2010) evaluated the effectiveness of VRT in combination with other training techniques and reported effectiveness for training outcomes including trainees' self-reports of change and thinking habits. Bloomberg, West and lacono (2003) showed improvements in staff members' communicative ability and the impact of this on their client's behaviour.

More recently, studies have evaluated the effectiveness of standalone VRT. This has found effectiveness for training outcomes such as staff members' use of supportive 
communication skills (Smidt, Baladin, Reed \& Sigafoos, 2007) and quality of interaction between staff and clients (Damen, Kef, Worm, Janssen \& Schuengel, 2011). Furthermore, Rombouts, Meuris, Maes, De Meyer and Zink (2016) found VRT was more effective for staff learning outcomes than traditional training techniques.

As previously noted, research into the use of VRT for staff supporting adults with learning disabilities was conducted in residential care settings. Yet as adults with learning disabilities have the opportunity to remain in education until they are 25 , many of their key communication partners are educational support staff. Currently, no research in the United Kingdom has investigated whether VRT is effective for staff working with adults with learning disabilities in educational settings. Whilst previous research hints VRT may be effective for these staff, this cannot be guaranteed as the makeup of support staff in residential versus educational contexts varies considerably. For instance, in comparison to residential contexts, educational contexts often include direct staff with a wide range of skill sets, e.g. qualified teachers, learning support assistants and lunchtime supervisors.

This study addresses the current gap in the literature by investigating whether VRT may be an effective tool for training client-centred communication skills with staff in a special education needs setting. Ten staff with a range of skill sets and experience of working in an education setting for adults with learning disabilities were trained to use client-centred communication strategies tailored to support a specific learner.

Moreover whilst the recent UK Government consultation (DHSC, 2019) does not cover staff working in education settings, the focus on mandatory training for those working with adults with learning disabilities warrants further investigation into the effectiveness of 
British Journal of Learning Disabilities Manuscript ID BLD-19-0027.R2 Accepted version. 11/12/19

training techniques such as VRT and how they can be applied to various sectors that support people with learning disabilities. 
British Journal of Learning Disabilities Manuscript ID BLD-19-0027.R2 Accepted version. 11/12/19

\section{METHOD AND PROCEDURE}

The study was conducted in partnership with a local university and received full ethical approval from the University Research Ethics Committee. Written consent was given by all research. For learners who were deemed to lack the mental capacity necessary to consent to being filmed, a best interest decision was made with their parents/carers and staff at the College. The research team received training and a handout from the College's speech and language therapist (SLT) in the process of VRT. This included how to introduce, facilitate selfreflection and set goals.

\section{Settings and Participants}

The research was carried out at a non-residential, specialist college for $16-25$ year olds with learning disabilities and autistic spectrum disorder, offering bespoke educational opportunities. Henceforth, these young people will be referred to as 'learners'.

\section{Learners}

Three learners (L1, L2, L3) from different classes at the College were selected to take part in the project. A brief profile of the three learners can be seen in Table 1, including each learner's three key prescribed communication strategies. 


\begin{tabular}{|c|c|c|c|c|}
\hline Learner & $\begin{array}{c}\text { Age } \\
\text { (years) }\end{array}$ & Diagnosis & $\begin{array}{l}\text { Year at } \\
\text { college }\end{array}$ & $\begin{array}{l}\text { Communication strategies for staff to use (specific } \\
\text { to learner) }\end{array}$ \\
\hline L1 & 20 & $\begin{array}{l}\text { Autism } \\
\text { Severe } \\
\text { learning } \\
\text { disability }\end{array}$ & $1^{\text {st }}$ & $\begin{array}{l}\text { 1. I use single words when giving L1 instructions } \\
\text { 2. I show } L 1 \text { the object of reference / gesture when } \\
\text { giving an instruction } \\
\text { 3. I respond when L1 initiates communication (e.g. } \\
\text { Intensive Interaction techniques* / mirroring / } \\
\text { eye contact) }\end{array}$ \\
\hline L2 & 22 & $\begin{array}{l}\text { Severe } \\
\text { learning } \\
\text { disability } \\
\text { Moderate } \\
\text { hearing } \\
\text { impairment - } \\
\text { bilateral } \\
\text { hearing aid }\end{array}$ & $3^{\text {rd }}$ & $\begin{array}{l}\text { 1. I use } 1-2 \text { key words when giving } L 2 \text { instructions } \\
\text { 2. I back up what I'm saying to } L 2 \text { using Makaton } \\
\text { sign or natural gesture } \\
\text { 3. I provide or prompt } L 2 \text { to use visual cues to } \\
\text { support his expression, e.g. Grid Player**, } \\
\text { symbols, drawings \& objects }\end{array}$ \\
\hline L3 & 20 & $\begin{array}{l}\text { Autism } \\
\text { Severe } \\
\text { learning } \\
\text { disability }\end{array}$ & $2^{\text {nd }}$ & $\begin{array}{l}\text { 1. I use 1-2 key words when giving L3 instructions } \\
\text { 2. I support L3's expression by encouraging him to } \\
\text { use his communication book, Grid Player or } \\
\text { drawings } \\
\text { 3. I speak to L3 using a confident tone of voice }\end{array}$ \\
\hline
\end{tabular}

Table 1: Learners' profiles, including the three key prescribed communication strategies.

\section{$\underline{\text { Staff }}$}

Ten staff members (P1-P10), including Special Education Needs teachers, senior Learning Support Assistants, Learning Support Assistants and a lunchtime supervisor were recruited via quota sampling following a presentation to all staff.

.Participants varied in length of time working with adults with learning disabilities (from less than one to over 30 years) and also length of time in their role (less than a week to two years). Participants had a range of qualifications, including vocational teacher qualifications and National Vocational Qualifications. All participants had received previous 
communication training and attended a weekly, 30 minute training session delivered by the College's Speech and Language Therapist (SLT).

\section{Procedure}

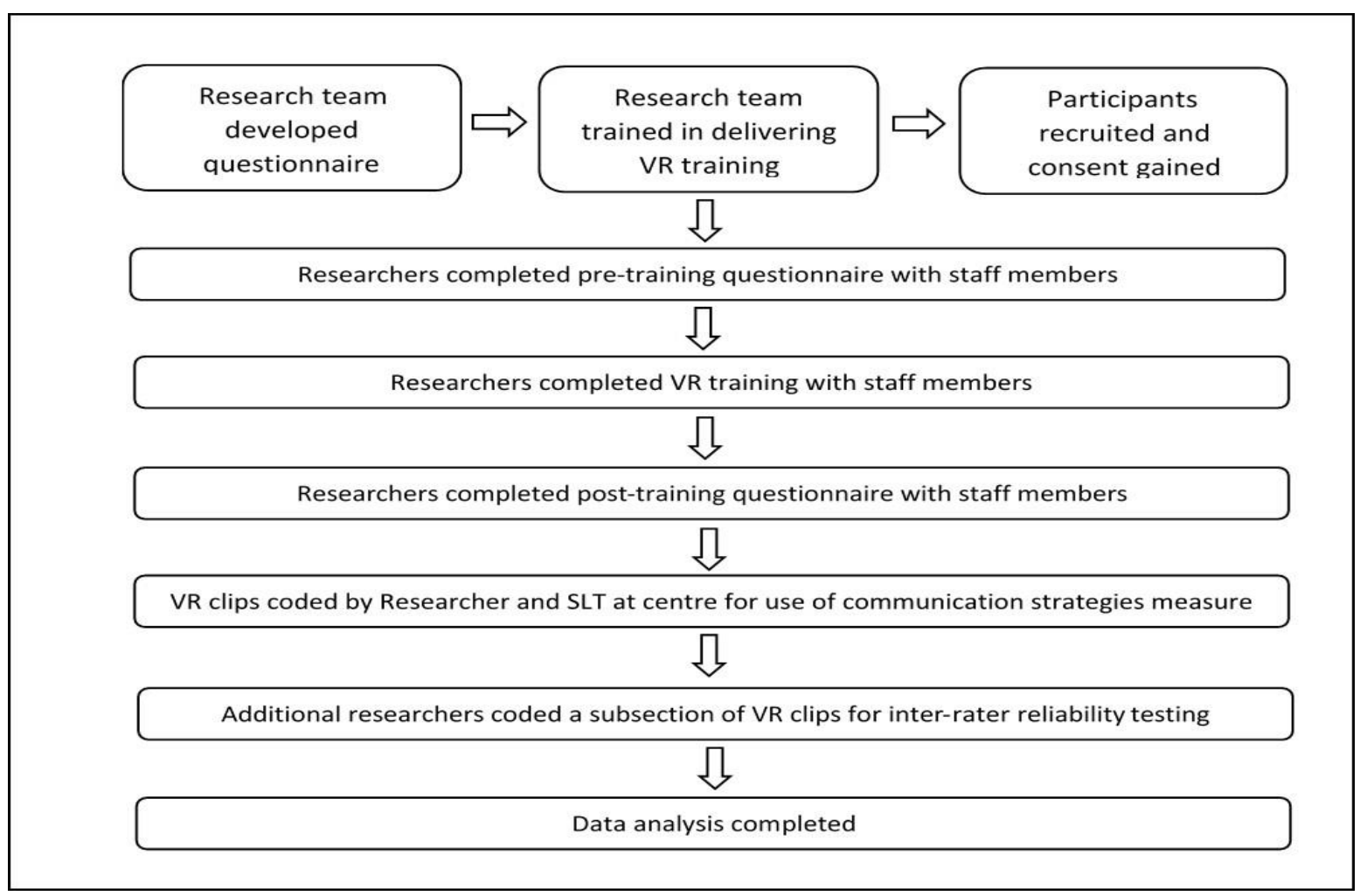

Figure 1: Key elements of the procedure in chronological order.

\section{VRT procedure}

A pre-experimental one group pre-test-post-test design was utilised. Participants completed VRT and training evaluation measures were taken before and after. Each member of the research team was allocated a group consisting of one learner and $3-4$ participants

The pre- and post-training questionnaires were completed with participants one week prior to the start of VRT and one week after, respectively. To remove bias, each member of the research team completed the questionnaires with a group of participants they would not be working with directly. See Figure 1 for procedure chronology. 
British Journal of Learning Disabilities Manuscript ID BLD-19-0027.R2 Accepted version. 11/12/19

VRT was tailored to support each learner's communication targets. Training focused on participants using communication strategies devised by the College's SLT, which were openly available to all participants as a part of the learner's 'communication passport'.

The training consisted of three VRT sessions during a three week period, as shown in Figure 2. On occasion due to practical restrictions, such as staff absence, some sessions were carried over to the following week.

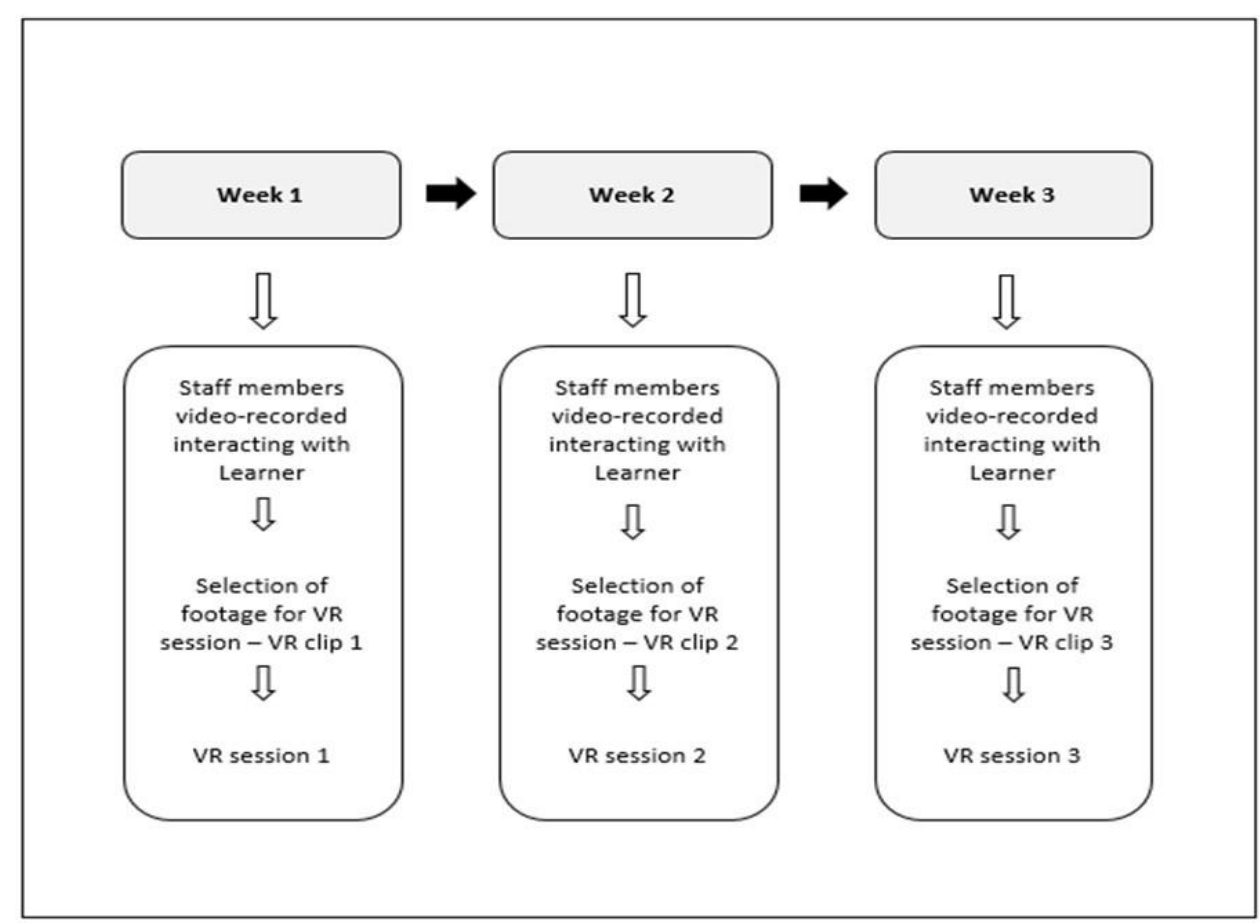

Figure 2: Visual representation of key elements of VRT

The researchers used a tablet device to film each participant interacting with the learner. Participants engaged in activities that elicited use of the learner's communication strategies.

Filming lasted for approximately ten minutes or until sufficient footage to reflect on was obtained.

Each researcher then reviewed their VR clips and selected 2-5 minutes of footage that displayed the participant engaging in activities where the communication strategies were 
utilised. This ensured footage viewed during VRT sessions was relevant and would encourage meaningful and balanced discussion.

A $20-30$ minute, one-to-one session with each participant then took place, mostly, on the same day as filming. The handout previously mentioned provided structure whereby participants were reminded of the learner's communication strategies and that they would be self-reflecting on their use of these once they had viewed the VRT clip. VRT clips were played and paused following each opportunity to use the learner's communication strategies. Participants were then prompted to self-reflect on their use of the strategies. Facilitation techniques were utilised to encourage meaningful reflection, including open questions, scaffolding, reinforcement, expansion and re-watching clips. Positive reinforcement was also used to focus on strengths and good practice. Following this, participants were asked to prioritise one of the strategies to focus on for the following VRT session.

\section{Training evaluation measures}




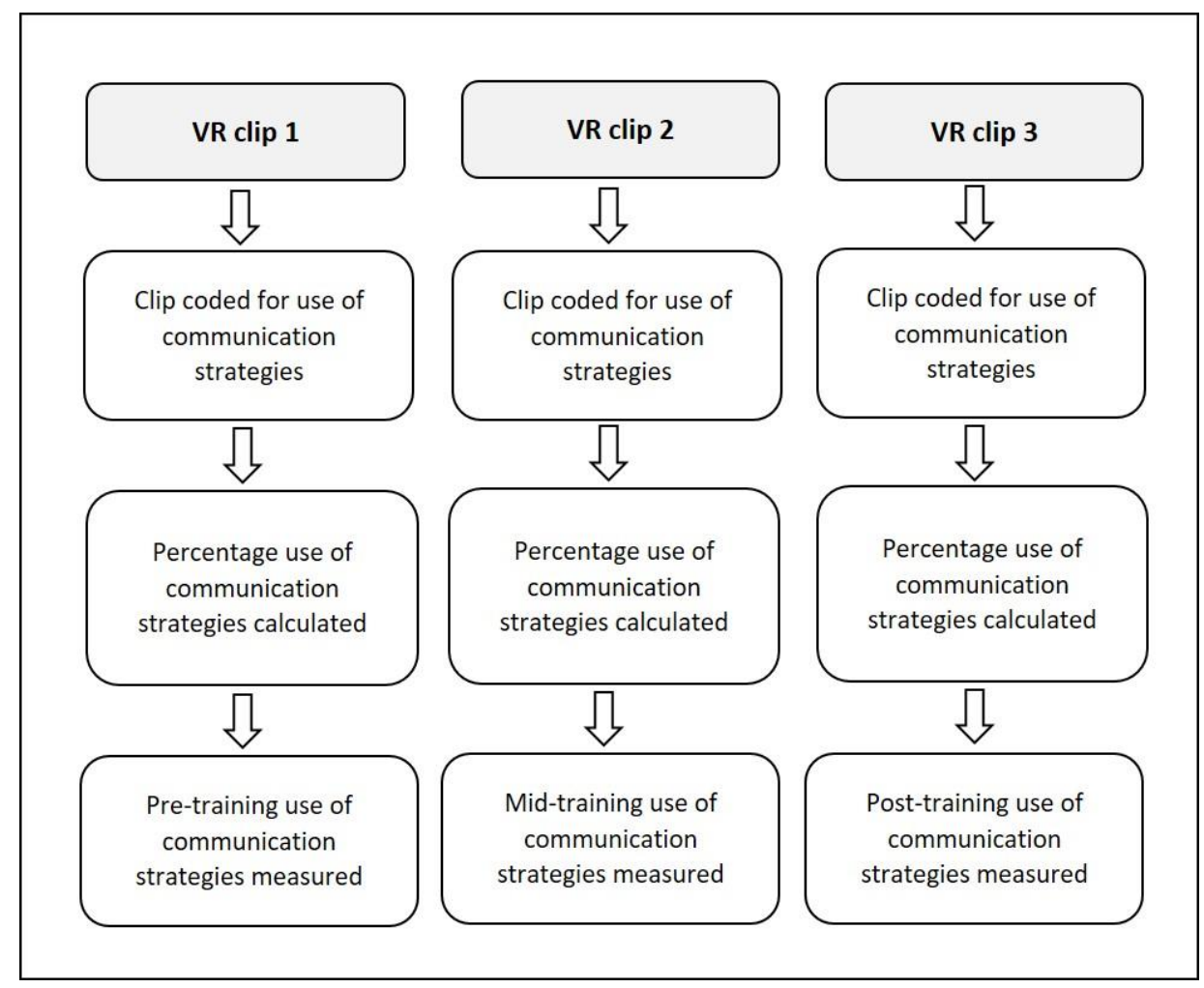

Figure 3: Visual representation of how VRT clips were used to calculate pre-training, midtraining and post-training use of communication strategies measures

To measure the use of communication of strategies, each VRT clip was coded by the research team and the College's SLT. To remove bias, coders were blind to the week of the clips. Additionally, each researcher did not code the clips of the participant they worked with directly. Coders identified each opportunity for communication strategies to be used and whether the participant used it. Percentages were then calculated by analysing the total number of opportunities for strategy use and the total number of strategy use for each VRT clip. See Figure 3 for visual representation of coding procedure. To determine reliability of this measure, three external coders were recruited to code a subset of VRT clips: two VRT clips of each participant were randomly selected for reliability coding, representing $25 \%$ of the total videos coded. All external coders 
British Journal of Learning Disabilities Manuscript ID BLD-19-0027.R2 Accepted version. 11/12/19

were Master level students in the final year of a speech and language sciences degree programme and thus deemed to have adequate baseline knowledge and skill for coding.

The questionnaires developed were based on previous literature on training evaluation, discussion with the College's SLT and feedback from a focus group of staff at the College not taking part in the project. In addition to participant demographics, information was collected about participants' self-efficacy, their preconceptions of training and their previous or current VRT training experience.

\section{Self-efficacy}

These questions measured the participants' self-efficacy to use communication strategies. This was based on literature on the design of self-efficacy measures which indicates that such measures should include three content domains (Kitching, Cassidy, Eachus \& Hogg, 2011) and a gradation of challenge (Bandura, 2006). Responses were measured on a fivepoint rating scale from 'strongly disagree' to 'strongly agree', as shown in the example in Figure 4. 


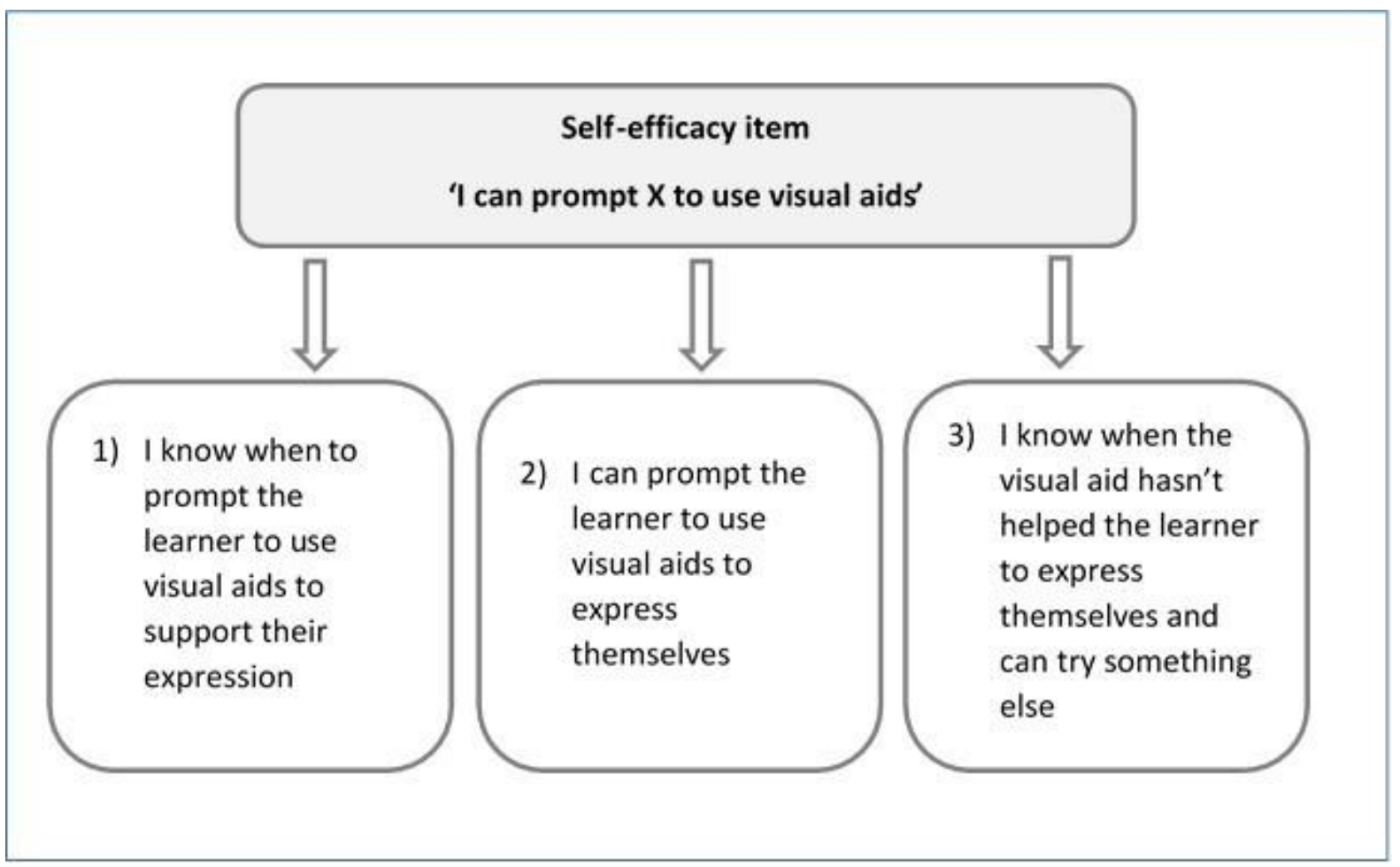

Figure 4: Example of self-efficacy item

\section{Pre-conceptions of training and training experience}

The items in this section of the questionnaires were based on the questionnaire used in a project that evaluated a communication training package provided at a care home for disabled adults (Bloch \& Maxim, 2010). This measured what participants were expecting from VRT, how they experienced it and what feedback they had on the process. 


\section{RESULTS}

\section{Inter-rater reliability (IRR) results}

Two two-way absolute, average-measures intra-class correlations (ICCs) were selected to assess internal and external inter-rater reliability (IRR) for coding of VRT clips. For all internal and external IRR, the resulting ICCs were in the excellent range, ICC $=0.996$, 0.999 and 0.905 for internal and ICC $=0.982,0.987$ and 0.998 for external (Cicchetti, 1994). This indicates that VRT clips were coded similarly across researchers. Thus, the use of the communication strategies measure was deemed suitably reliable for data analysis.

\section{Use of communication strategies}

To determine whether VRT resulted in a change in participants' use of communication strategies, descriptive statistics comparing pre and post-training measures were completed.

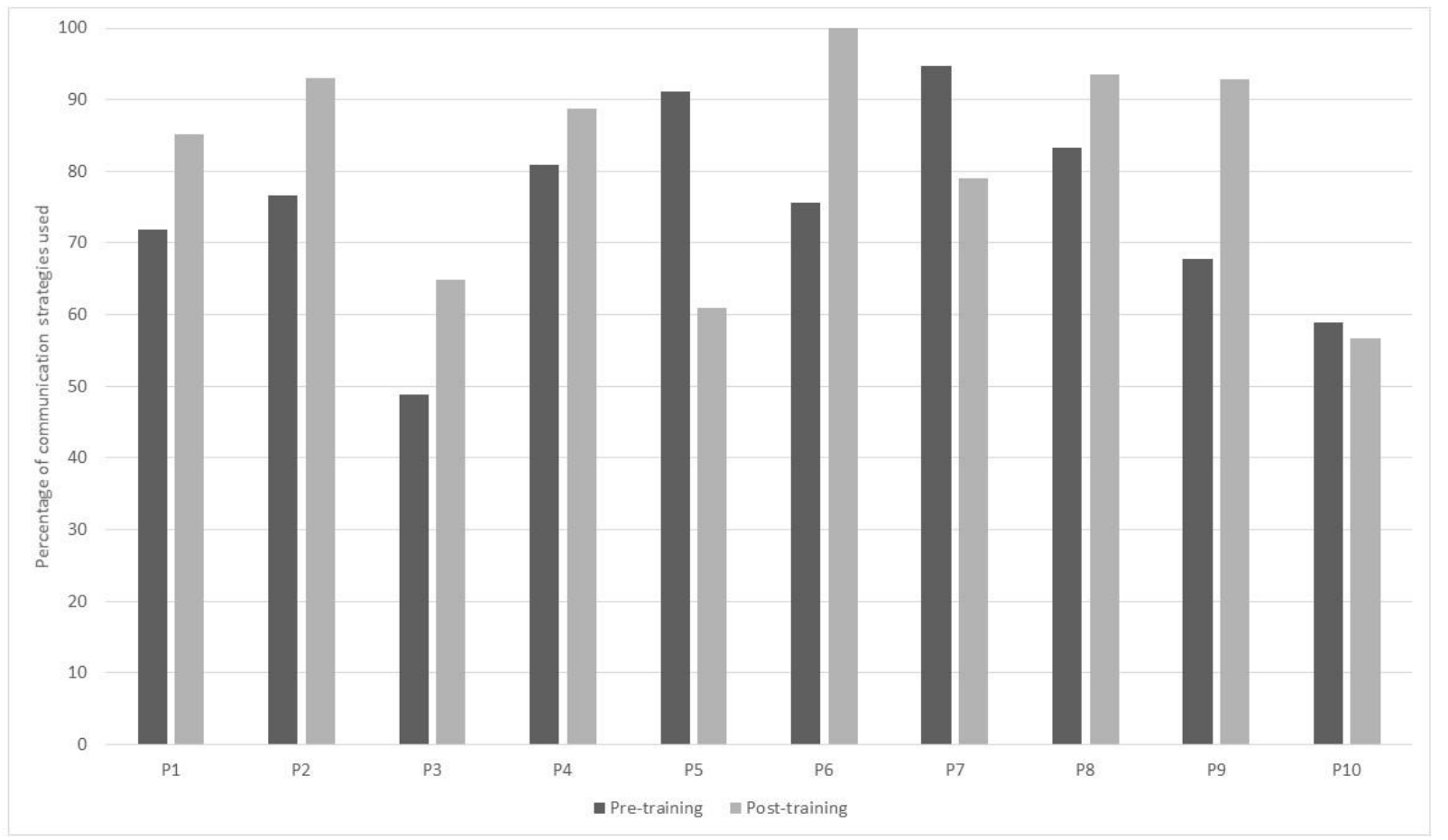


Figure 5. Mean percentage use of communication strategies by staff members across time points, averaged across communication strategy.

As Figure 5 demonstrates, 7 out of the 10 participants increased their overall use of communication strategies after VRT. This ranged from an increase of $8 \%$ to $25 \%$ across participants.

P1, P2, P4, P6, P8 and P9 performed considerably well on average before training. By the end of training, each of these participants were using the communication strategies between $85 \%$ and $100 \%$ of the time.

P10 performed less well on average pre-training, with $58 \%$ use of communication strategies. Their average use of strategies did not change much after VRT. However, it should be noted that a lack of opportunities to implement communication strategy two specifically may have impacted the average score across communication strategies used.

Conversely, before training, P5 and P7 performed substantially well, using the communication strategies on average $91 \%$ and $95 \%$ of the time respectively. However both participants decreased in their overall use of strategies after training, by $30 \%$ and $16 \%$ respectively. Again, this may be due to a lack of opportunities to use strategy two at week three versus week one.

\section{Self-efficacy ratings}

Descriptive statistics were completed, averaged across all self-efficacy items to determine whether VRT resulted in an increase in participants' self-efficacy to use communication strategies. 
As shown in Figure 6, 9/10 participants' self-efficacy ratings increased between the pre and post-training stages and one did not change (P10). All participants were relatively confident at baseline, with none rating their self-efficacy to use communication strategies negatively. Four participants rated their self-efficacy as between 'not sure' and 'agree' at baseline and three out of the four moved to between 'agree' and 'strongly agree' post-training. P3 increased slightly, but remained in the same rating

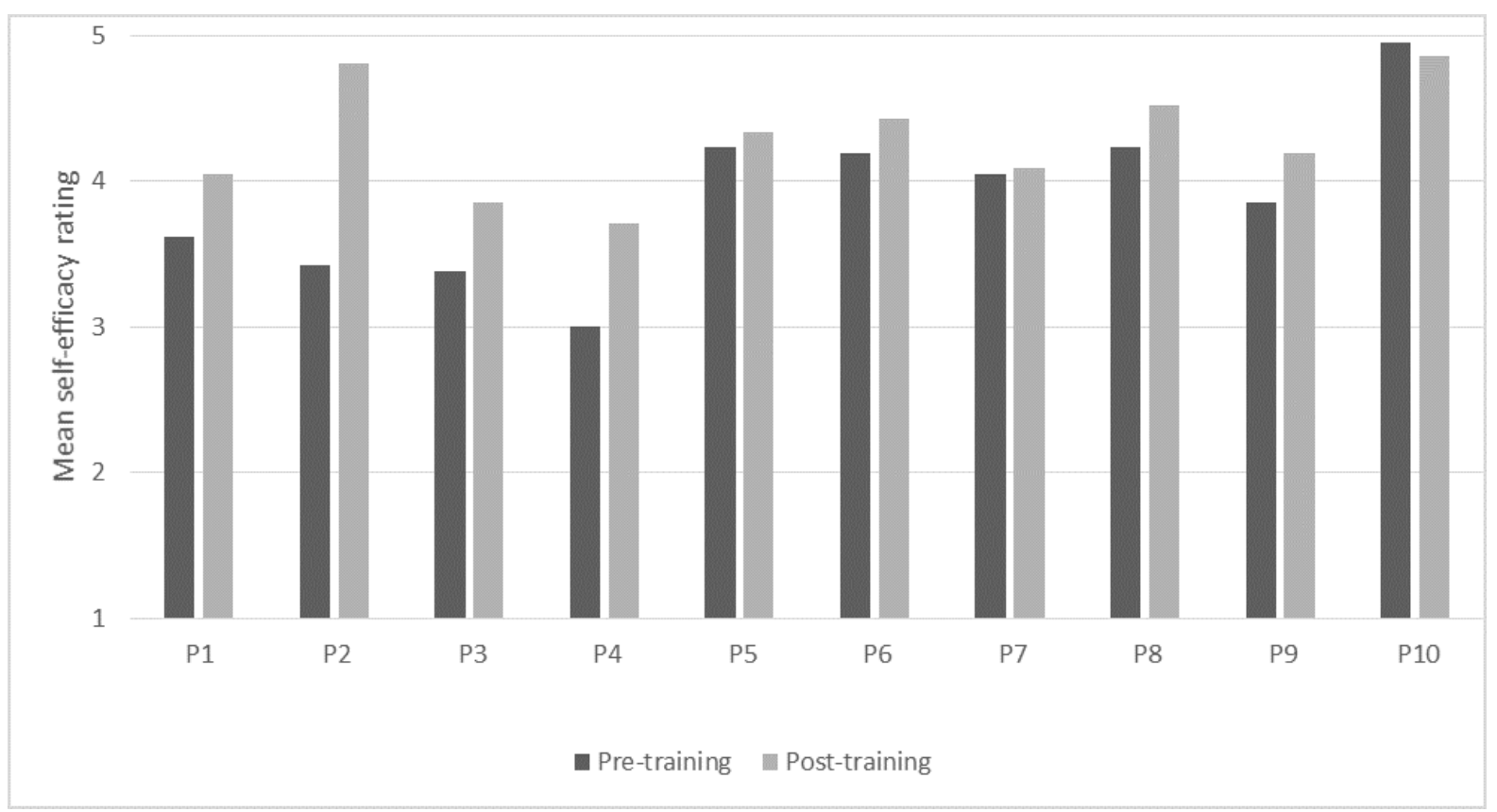

Figure 6: Mean self-efficacy ratings by staff members across time points

\section{Pre-conceptions of training and training experience}

A content analysis (Elo \& Kyngäs, 2008) was performed on the qualitative data gained from the questionnaire, which identified key factors to evaluate how staff experienced VRT.

\section{Experience of VRT}

All participants viewed their VRT experience as positive, with 7/10 rating it 'excellent' and 3/10 'good'. Furthermore, all participants reported that they thought the training worked 
well in the setting and $8 / 10$ would take the opportunity to participate in future VRT. The two participants who said they would not want to participate again reported higher levels of video-related anxiety. Participants discussed the benefits of video as an objective tool to observe themselves $(8 / 10)$ and to provide the opportunity to reflect on how they communicate (10/10). The experience of being able to 'see themselves' and not making assumptions about how they perform was seen as valuable. Overall, 6/10 participants expressed some level of anxiety being videoed. Concerns included: being self-aware, fear of making mistakes and not behaving naturally. However, four out of these six participants reported that with time and after seeing the benefits, their video-related anxiety reduced.

\section{Learning outcomes}

All participants reported a key learning outcome as being their professional development and use of the suggested communication strategies. This included comments about learning new skills and developing consistency in their current practice. Additionally, two participants noted that the learning outcomes achieved were transferable to the other learners they supported. All commented that video supported their reflection, yet three participants specifically stated VRT improved their ability to reflect on their skills and be more receptive to feedback.

\section{Structure and facilitation}

The majority of participants agreed that three VRT sessions were optimal to see improvements over time and implement change (7/10). Some participants noted that review sessions every few months may support maintenance of new skills (3/10). Moreover, participants noted they preferred $1-1$ sessions $(7 / 10)$ as they are confidential and alleviate feelings of pressure and judgement. Participants provided constructive feedback, which 
British Journal of Learning Disabilities Manuscript ID BLD-19-0027.R2 Accepted version. 11/12/19

included difficulties with fitting VRT into busy working days $(7 / 10)$ and having flexibility to focus on more than the three pre-selected strategies. 
British Journal of Learning Disabilities Manuscript ID BLD-19-0027.R2 Accepted version. 11/12/19

\section{DISCUSSION}

The present study sought to investigate whether VRT may be an effective tool for training client-centred communication skills in staff supporting adults with learning disabilities in an education setting. The outcomes of the study will now be addressed alongside caveats for interpreting findings.

Overall, all participants made gains in at least one area examined. 7/10 participants increased their overall use of the communication strategies, 9/10 participants increased their self-efficacy to use communication strategies after VRT and 10/10 participant's rated their VRT experience as positive.

The finding regarding increased overall use of communication strategies by staff is in line with previous research investigating the effectiveness of VRT solely. For instance, Smidt et al. (2007) found an increase in staff's supportive communication skills and Damen et al. (2011) found an increase in quality of interaction between staff and clients.

Moreover, the findings regarding increased self-efficacy to use communication strategies is in keeping with previous research. For instance, Koski et al. (2010) found that training resulted in changes in staff members' thinking habits concerning adults with learning disabilities.

Whilst the findings discussed above do indicate positive outcomes following VRT, due to a number of limitations of the present study, caution must be taken when considering whether VRT itself resulted in these outcomes.

Firstly, positive outcomes must be acknowledged with the caveat of the pre-test-post-test study design. A control group in any form was not utilised as this was not within the study's 
practical remit. As a result, this allows several confounding extraneous variables that may have jeopardised internal validity, e.g. other sources of training. Whilst there are ethical issues of control groups in research with clinical populations, a possible solution could be to utilise a waitlist control group (RCSLT, 2009).

Similarly, findings must be considered with the knowledge of a small sample size and limited statistical analysis. A larger sample size was not within the practical remit of the present study and inferential statistics were consequently deemed inappropriate. Whilst descriptive statistics help summarise data in a meaningful way to allow observation of patterns, they do not allow for conclusions such as whether there is a meaningful difference between two time points. Moreover, as only a small sample of staff participated, findings cannot be interpreted to be representative of the target population.

Whilst the use of communication strategies measure was objective and found to have high inter-rater reliability, it may have lacked validity due to varying number of opportunities to use communication strategies present in VR clips. In circumstances where there was a stark difference between the number of opportunities in VR clips at different time points, the comparison between the derived measures of communication strategies at these different time points could be compromised. A possible solution is to adjust the activities filmed during VR sessions. As it can be difficult to structure sessions too rigidly, due to the need to work flexibly with this client group, activities should allow opportunities to use the communication strategies multiple times per VRT session for valid comparison. Therefore, additional time should be factored in to investigate further potentially more fruitful activities. 
British Journal of Learning Disabilities Manuscript ID BLD-19-0027.R2 Accepted version. 11/12/19

However, in spite of these limitations, this study design could be a useful starting point for future researchers engaging in training studies across health, social care and other education settings.

As highlighted in the review of theoretical underpinnings of VRT in the introduction, objectively seeing oneself and self-reflecting on behaviour appears to underpin the effectiveness of VRT. Nearly all participants affirmed the value of actually seeing what they did and having the opportunity to self-reflect.

Self-reflection through observing oneself on a video is a key ingredient for VRT's effectiveness. Yet, this does additionally introduce a potential area of difficulty namely training acceptability, i.e. how satisfied individuals are with a training programme. This is important to consider as acceptable training is ethically justified, leads to high staff satisfaction and lower drop-out rates (Davis, Rawana \& Capponi, 1989). In the present study, whilst all staff evaluated the training positively, 2/10 reporting they would not complete VRT again due to video-related anxiety. The gains made by these participants may have been limited by their anxiety about being videoed - lowering the acceptability of the training. To optimise VRT's effectiveness, future VRT could provide staff with increased autonomy concerning being videoed which may improve training acceptability. For instance, staff could video themselves which may alleviate some anxiety of being filmed by an observer. This approach of VRT has been used successfully in other applications of VRT (Beeke et al., 2013) and thus is likely to be successful in an adult learning disabilities context with appropriate advice and support.

Similarly, having a supportive and constructive facilitator is likely to have contributed to training acceptability and provided an environment whereby participants were able to fully 
self-reflect without judgement. The present study utilised a "balanced reflection" style of facilitation, that is, to identify and reinforce positive communication behaviours, identify and provide alternatives to undesirable communication behaviours (Lock et al., 2001) and subsequently to affect behaviour change (Fukkink et al., 2011). Many participants commented how it was helpful to consider both positive areas and areas for improvement. Future VRT could further boost its effectiveness by ensuring there is adequate time for participants and facilitators to build rapport and ensure a balanced reflection style is used.

Whilst VRT is inherently tailored to individual participants as it focuses on self-reflection of personal practice, the analysis of this set of data in which staff are all quite different has unearthed factors relating to all staff that could influence VRT's effectiveness. These include baseline communication skills and self-reflection skills.

Relating to baseline communication skills, the majority of participants presented as relatively well skilled in overall use of these strategies at baseline. For instance, 7/10 participants presented as overall using communication strategies at least $70 \%$ of the time or above, with $2 / 7$ of these performing near ceiling level. Correspondingly, just $3 / 10$ participants presented as overall using communication strategies below $70 \%$ of the time. Whilst the present study does not have adequate participant numbers and subsequent power to compare effectiveness of VRT for high versus low skilled staff members and 5/7 of those who were well skilled at baseline did make gains, the focus on using communication strategies that they were already well skilled in using may have limited their opportunity to develop their skills further. Conversely, for lower skilled staff members, the focus on using specific communication strategies may have been a beneficial starting point to develop their key skills. 
The ability to self-reflect is likely to impact the effectiveness of VRT as self-reflection is an inherent component in the training itself and is integral to the theoretical basis. In the present study, staff members are likely to have had varying self-reflection abilities effecting their engagement with VRT. For instance, P1 appeared to have strong self-reflection skills at baseline, whereas P2 appeared to struggle to self-reflect throughout VRT. It may be that individuals with a low level of ability to self-reflect require additional support to develop these skills before starting the VRT training.

To optimise its effectiveness for all staff members, future VRT should include a fully individualised training programme that focuses on facilitators and barriers to behaviour change. This could include having a baseline measurement of participants' communication and self-reflection skills. The VRT facilitator could then adapt training to suit each participant depending on the outcomes of these baseline measures and offer additional training to those participants that require it. Relating to baseline communication skills, low skilled staff members could begin with training as demonstrated in this study that analyses and develops the use of set communication strategies. Whereas, the higher skilled staff members who perform well at using communication strategies at baseline could begin with training that focuses on their interactions with clients and with setting their own goals. These staff member could then assist SLTs in delivering VRT to lower skilled colleagues in a cascade fashion. Previous literature on staff training using VRT has successfully trained communication skills by focusing on interactions, (Beeke et al., 2013) and providing cascade training via a high skilled staff member (Johnson et al., 2014), thus indicating that these may be useful approaches. 


\section{Conclusion}

The present study provides exciting findings showing that VRT is a useful tool for training communication skills in staff supporting adults with learning disabilities in an education setting. Earlier government strategy advocated that training of staff working with adults with learning disabilities should be client-centred ( $\mathrm{DOH}, 2009)$. In line with the recent consultation (DHSC, 2019) concerning training, the present study takes this one step further and suggests that training should additionally be staff-centred and tailored to individual staff members' skill sets and experience to increase effectiveness. VRT can be applied to the consultation strategy of tiered training delivery, by being implemented by highly skilled Tier 3 professionals to Tier 2 staff who provide direct support to people with learning disabilities.

The recommendations for improving the study design, as outlined above, provide future researchers with guidance to contribute substantial evidence for the use of client and staffcentred VRT for staff training. Further studies will continue to examine how training can be adapted to be more effective. The ultimate aim of staff training is to support adults with learning disabilities to communicate successfully, to achieve positive destinations in life and fully exercise their human rights (RCSLT, 2013). 


\section{REFERENCES}

Arenstein, B., \& Lipson, N. (2013). Training communication partners of adults who use AAC: Finding the evidence. Paper presented at the Communication Matters Conference, Leeds.

Baker, V., Oldnall, L., Birkett, E., McCluskey, G., \& Morris, J. (2010). Adults with learning disabilities (ALD). Royal College of Speech and Language Therapists Position Paper. London: Royal College of Speech and Language Therapists. https://www.rcslt.org/members/publications/ald position paper [accessed 10 June 2016]

Bandura, A. (2006). Guide for constructing self-efficacy scales. In Pajares, F. \& Urdan, T. (Eds.), Self-efficacy beliefs of adolescents. (Greenwich, CT: Information Age) pp. 307-337.

Beeke, S., Sirman, N., Beckley, F., Maxim, J., Edwards, S., Swinburn, K., \& Best, W. (2013). Better Conversations with Aphasia: an e-learning resource. Available at: https://extend.ucl.ac.uk [accessed on 3 June 2016]

Bloch, S., \& Maxim, J. (2010). Leonard Cheshire Disability Communication Project. Communication Matters, 24(1), 31.

Bloomberg, K., West, D. \& lacono, T.A. (2003). PICTURE IT: an evaluation of a training program for carers of adults with severe and multiple disabilities. Journal of Intellectual and Developmental Disability, 28(3), 260-262.

Cicchetti, D. V. (1994). Guidelines, criteria, and rules of thumb for evaluating normed and standardized assessment instruments in psychology. Psychological assessment, 6(4), 284. 
Damen, S., Kef, S., Worm, M., Janssen, M. J., \& Schuengel, C. (2011). Effects of videofeedback interaction training for professional caregivers of children and adults with visual and intellectual disabilities. Journal of Intellectual Disability Research : JIDR, 55(6), 581-95.

Davis, J. R., Rawana, E. P. and Capponi, D. R. (1989). Acceptability of behavioral staff management techniques. Behavioral Interventions, 4(1), 23-44

Department of Health. (2001). Valuing People: A New Strategy for the 21st Century. London: Department of Health

Department of Health. (2009). Valuing People Now: A new three year strategy for people with learning disabilities. London: Department of Health

Department of Health and Social Care. (2019). Learning disability and autism training for health and care staff https://assets.publishing.service.gov.uk/government/uploads/system/uploads/attachment data/file/778129/Learning_disability_and_autism_training_for_health_and_care_staff_co nsultation_document.pdf

Dobson, S., Upadhyaya, S., \& Stanley, B. (2002). Using an interdisciplinary approach to training to develop the quality of communication with adults with profound learning disabilities by care staff. International Journal of Language \& Communication Disorders, 37(1), 41-57.

Elo, S., \& Kyngas, H. (2008). The qualitative content analysis process. Journal of Advanced Nursing, 62(1), 107-115.

Enderby, P., Pickstone, C., John, A., Fryer, K., Cantrell, A., \& Papaioannou, D. (2009). Resource manual for commissioning and planning services for SLCN. Learning Disability. London: Royal College of Speech and Language Therapists. Available: 
https://www.rcslt.org/speech_and_language_therapy/commissioning/learning_ disabilities_plus_intro [accessed 3 June 2016]

Fukkink, R. G., Trienekens, N., \& Kramer, L. J. (2011). Video feedback in education and training: Putting learning in the picture. Educational Psychology Review, 23(1), 45-63.

Johnson, J., Pepperell, C., \& Hutchinson, J. (2014). Implementing Total Communication strategies across staff teams: Training staff to use video reflection. Paper presented at the meeting of the ALD Clinical Excellence Network, London.

Kelly, A. (2002). Working with Adults with a Learning Disability. Milton Keynes: Speechmark.

Kennedy, H., Landor, M., \& Todd, L. (2011). Video interaction guidance: A relationshipbased intervention to promote attunement, empathy and wellbeing. (London, England: Jessica Kingsley).

Kitching, J., Cassidy, S., Eachus, P, \& Hogg, P. (2011). Creating and validating self-efficacy scales for students. Radiologic technology, 83(1), 10-19.

Koski, K., Martikainen, K., Burakoff, K., \& Launonen, K. (2010). Staff members' understandings about communication with individuals who have multiple learning disabilities: A case of Finnish OIVA communication training. Journal of Intellectual \& Developmental Disability, 35(4), 279-89.

Kurtz, S., Silverman, J., \& Draper, J. (2005). Teaching and learning communication skills in medicine (2nd ed.). (Oxford: Radcliffe Medical). 
Lock, S., Wilkinson, R., Bryan, K., Bruce, C., Edmundson, A., Maxim, J., \& Moir, D. (2001). SPPARC: Supporting Partners of People with Aphasia in Relationships and Conversation. A Resource Pack. (Bicester: Speechmark).

Money, D. (1997). A comparison of three approaches to delivering a speech and language therapy service to people with learning difficulties. European Journal of Disorders of Communication, 32(4), 449-466.

Rombouts, E., Meuris, K., Maes, B., De Meyer, A. M., \& Zink, I. (2016). Video Feedback in Key Word Signing Training for Preservice Direct Support Staff. Journal of Speech, Language and Hearing Research, 59(2), 342-348.

Royal College of Speech and Language Therapists. (2013). Five Good Communication Standards, RCSLT London. Available:

https://www.rcslt.org/news/docs/good_comm_standards [accessed 4 July 2016]

Royal College of Speech and Language Therapists. (2009). Resource manual for commissioning and planning services for SLCN - learning disabilities, RCSLT London. Available:

https://www.rcslt.org/speech_and_language_therapy/commissioning/learning_ disabilities_plus_intro [accessed 4 July 2016]

Smidt, A., Balandin, S., Reed, V., \& Sigafoos, J. (2007). A communication training programme for residential staff working with adults with challenging behaviour: Pilot data on intervention effects. Journal of Applied Research in Intellectual Disabilities, 20(1), 16-29. 
British Journal of Learning Disabilities Manuscript ID BLD-19-0027.R2 Accepted version. 11/12/19

Van Oorsouw, W. M., Embregts, P. J., Bosman, A. M., \& Jahoda, A. (2009). Training staff serving clients with intellectual disabilities: A meta-analysis of aspects determining effectiveness. Research in Developmental Disabilities, 30(3), 503-511. 